\title{
Research for leveraging food policy in universal eating disorder prevention
}

\author{
Rachel F. Rodgers $\mathrm{PhD}^{1,2}$ () | Kendrin Sonneville ScD, RD
}

\author{
${ }^{1}$ Department of Applied Psychology, Bouve \\ College of Health Sciences, Northeastern \\ University, Boston, Massachusetts \\ ${ }^{2}$ Department of Psychiatric Emergency and \\ Acute Care, Lapeyronie Hospital, CHRU \\ Montpellier, Montpellier, France \\ ${ }^{3}$ Department of Nutritional Sciences, \\ University of Michigan School of Public \\ Health, Ann Arbor, Michigan
}

\begin{abstract}
Policy and legislation have emerged as important levers for universal prevention efforts in the context of eating disorders. However, to date, little attention has been paid to generating research that will inform opportunities to regulate the food environment, specifically the way that food is produced and marketed. The present paper aims to lay out a framework for research that will examine (1) the ways in which food industry may influence risk for eating disorders and (2) the impact of legislative efforts on eating disorder cognitions and behaviors. For these two pathways, specific examples of research that would serve to inform policy efforts aiming to decrease the risk for eating disorders by targeting the food environment are proposed. Overall, the present paper aims to issue a call for the eating disorder field to become involved in food policy and regulation.

KEYWORDS

food environment, policy, regulation, universal prevention
\end{abstract}

\section{1 | INTRODUCTION}

In recent years, policy and legislation have emerged as important levers for universal prevention efforts (Austin, 2016; Rodgers, Ziff, Lowy, Yu, $\&$ Austin, 2017). Moreover, for-profit industries that benefit from individuals experiencing body image and eating concerns (e.g., the diet, fashion, and beauty industries) have been implicated as important targets for macro-level intervention (Austin, 2016; Haines \& NeumarkSztainer, 2006). Although food industry practices, including the production and marketing of food, could influence risk for eating disorders, insufficient research aiming to inform or evaluate policy related to the regulation of the food environment has been undertaken by the eating disorder community to date. Two key areas of research warrant investigation. First, eating disorder researchers should examine how specific food industry practices, including the production and marketing of food, may influence eating disorder risk. Secondly, research on the impact of legislative efforts on eating disorder cognitions and behaviors is needed (Roberto \& Brownell, 2017). Such evaluations of the effects of policies targeting food industry on eating disorder risk are important to identify useful policy solutions. The present paper aims to lay out a framework for research that will accelerate universal prevention efforts by leveraging policies targeting the food environment, and calls for eating disorder researchers, clinicians, and advocates to become increasingly involved in this area of research.

\section{2 | RESEARCH TO IDENTIFY FOOD INDUSTRY PRACTICES THAT INCREASE EATING DISORDER RISK}

The modern food environment is characterized by the over-abundance and aggressive marketing of highly-processed foods and diet foods that may increase risk for eating disorders. Furthermore, youth may be particularly vulnerable to these practices given their emerging media literacy skills, as well as taste preferences (Harris \& Graff, 2011; Robinson, Borzekowski, Matheson, \& Kraemer, 2007). This is an important point as eating disorders also typically emerge during late childhood or adolescence (Haines \& Neumark-Sztainer, 2006). To contribute to the evidence supporting legislation targeting the food environment and food industry practices, more research related to the production and marketing of these foods is warranted.

\section{1 | Highly processed foods}

The food industry employs a number of practices to produce, market, and sell foods that may increase the risk for eating disorders. For example, by combining optimal levels of sugar, fat, and salt, the food industry engineers foods to be as rewarding as possible (Gearhardt, Grilo, DiLeone, Brownell, \& Potenza, 2011; Stice, Figlewicz, Gosnell, Levine, \& Pratt, 2013). Indeed, highly-processed foods, containing refined sugars and added fats, have been identified as being most associated with 
TABLE 1 Summary of strategic research directions

\author{
Strategic research area \#1: \\ Research to identify food industry practices that increase eating disorder risk
}

Highly-processed foods

- Clarify the processes through which the engineering of foods to be highly rewarding or limited in their capacity to satiate can increase eating disorder risk

- Examine the addictive-like characteristics of some eating behaviors, across multiple levels, including behavioral, psychological, and biological

- Examine the capacity for highly-processed foods to trigger addictive processes and loss-of-control eating, particularly in children

- Explore the role of highly-processed foods in the development of taste preferences and the capacity to recognize and respond to feelings of satiety, and how these are related to the development of disordered eating patterns

Diet foods

- Investigate potential biological and psychological mechanisms (e.g., restriction, craving, pressure to lose or control weight) linking the consumption of diet foods to loss-of-control eating

- Evaluate how health claims affect the perception of the taste, health, or satiating-potential of foods

- Examine how health claims influence food choice and purchasing, and whether individuals with higher levels of food or shape and weight preoccupation are differentially vulnerable to these effects

Strategic research area \#2:

Research on the impact of legislative efforts on eating disorder risk

- Evaluate the impact on eating disorder risk of changes to policy and legislation around nutritional labeling on packages, as well as in restaurants and other food outlets

- Examine the effect of different serving sizes on loss-of-control and binge eating, as well as restriction

- Characterize the effects of labeling and health claims on eating disorder risk

- Evaluate the impact of legislation implemented in other countries to examine its potential usefulness when translated to the other contexts

- Identify and evaluate new policy solutions related to the food environment and food industry practices

loss-of-control eating (Schulte, Avena, \& Gearhardt, 2015). In addition, animal models of binge eating have highlighted the role of highlyprocessed foods in triggering symptomatology (Hagan, Chandler, Wauford, Rybak, \& Oswald, 2003). Above and beyond the engineering of highly processed foods, the food industry may contribute to increasing eating disorder risk through the ways that it markets and sells these foods. Highly-processed foods are widely-available, served in large quantities, and heavily marketed. The wide-spread availability of highly-processed foods could lead to greater dietary restraint in susceptible individuals and could increase the risk for binge eating through the purchasing of these foods in large amounts, or the increased availability of these foods at home (Stirling, \& Yeomans, 2004). Preliminary evidence indicates that youth who experience loss-of-control eating are more susceptible to the effects of large portion sizes on overconsumption compared to their peers (English, Lasschuijt, \& Keller, 2015).

Future work might seek to further characterize or clarify the processes through which the engineering of foods to be highly rewarding or limited in their capacity to satiate can increase risk for eating disorders (Table 1). This would include examining the addictive-like characteristics of some eating behaviors, across multiple levels, including behavioral, psychological, biological, and neuroendocrinological. Studies examining the capacity for particular highly processed foods to trigger these addictive processes and loss-of-control eating would be useful, particularly in children. In addition, research should explore the role of highly processed foods in the development of taste preferences and the capacity to recognize and respond to feelings of satiety. In this way, research might examine the questions of how and when in the course of development the consumption of highly-processed foods influence taste preferences and satiety mechanisms, and in turn how these are related to eating disorder risk. Investigating the timing of the introduction of highly processed foods such that their effects on these processes are minimized could also be fruitful. A research agenda focusing on these questions could include cross-sectional, longitudinal, experimental, and intervention studies, aiming to clarify and quantify the role of highly processed foods in disordered eating behaviors.

\section{2 | Diet foods}

The food industry has capitalized on the rising preoccupation with weight control, by creating of numerous "diet" foods, that include ingredients, such as low-calorie artificial sweeteners to create reducedcalorie or "light" products. These foods may increase risk for eating disorders both through their ingredients but also the perpetuation of a culture of dieting. Consistent with this, data support the fact that consumption of artificially sweetened foods can increase sugar cravings (Yang, 2010), which could in turn increase binge eating or overeating. In addition, research has suggested that individuals underestimate the calorie-content of low-fat foods (Ebneter, Latner, \& Nigg, 2013), and may enjoy eating these foods less than their equivalents that are not marketed as low-fat ( $\mathrm{Ng}$, Stice, Yokum, \& Bohon, 2011), thus potentially amplifying dietary restriction. In this way, claims that foods are lower in calories or more healthy may influence individuals' food choices in ways that are paradoxically unhelpful, lead to increased restriction, cravings and loss-of-control eating (Schulte et al., 2015), and thereby increasing the risk of eating disorders.

Research related to the creation and marketing of diet foods could focus on examining the different pathways through which consumption of diet products might contribute to eating disorders. Specifically, research investigating both the potential biological and psychological mechanisms through processes of restriction, craving, and pressure to 
lose or control weight, linking the consumptions of diet foods to lossof-control eating would make an important contribution. In addition, research should focus on investigating the role of health claims in these pathways, as opposed to the effects of the diet foods themselves. In this way, it could be useful to evaluate how health claims affect the perception of the taste, health, or satiating-potential of foods, as well as how they influence food choice and purchasing, and whether individuals with higher levels of food or shape and weight preoccupation are differentially vulnerable to these effects.

\section{3 | RESEARCH TO EVALUATE EXISTING POLICY AIMING TO MODIFY THE FOOD ENVIRONMENT}

A second important focus of a program of research is to evaluate the effect of existing and emerging legislation on eating disorder risk to generate data that is useful for policy makers. A number of policies and proposals have emerged over the past years that would be important to evaluate, including those focused on issues such as portion size, calorie labeling, or taxing certain ingredients such as sugar (Brownell \& Frieden, 2009; Burton \& Kees, 2012; Vermeer, Steenhuis, \& Poelman, 2014). Regarding portion size in particular, a number of initiatives have been undertaken, ranging from voluntary pledges to regulations including in the US, UK, Australia, and Canada (Crino, Sacks, \& Wu, 2016). In the US, the Food and Drug Administration already requires a statement regarding portion sizes on the labels of foods, and is currently in the process of implementing changes to the description of portion sizes in the nutritional information included on labels. These changes aim to make food package labels easier to interpret. However, the normalization of larger portions could increase eating disorder risk through greater availability of craved-foods, or heightened dietary restriction in response to increases in reported calorie content (Herman, Polivy, Pliner, \& Vartanian, 2015; Kerameas, Vartanian, Herman, \& Polivy, 2015). Regarding calorie-labeling, recent regulations have required such labeling in restaurants in an effort to guide consumers towards lowercalorie options (Burton \& Kees, 2012). While such policies are welcome for increasing food industry transparency, the impact of such policies on calorie consumption has been limited (Long, Tobias, Cradock, Batchelder, \& Gortmaker, 2015; Sinclair, Cooper, \& Mansfield, 2014; Swartz, Braxton, \& Viera, 2011). Moreover, a number of concerns have been expressed regarding the ways in which such labeling might impact individuals with eating concerns, who experience high levels of preoccupation around calorie content, and heightened anxiety around food choices. Luckily, the few data available to date on how such policies may impact individuals at risk for eating disorders have so far not found evidence that they are harmful (Lillico, Hanning, Findlay, \& Hammond, 2015).

Building upon prior research of how policies aimed at modifying the food environment have affected consumer behavior, future studies should focus more specifically on the question of whether or how such policies impact risk for the development of eating disorders. Specifically, areas that would be useful could include evaluations of the impact on eating disorder risk of changes to policy and legislation around nutritional labeling on packages as well as in restaurants and other food outlets. Similarly, investigations might include examining the effect of different serving sizes on loss-ofcontrol and binge eating, as well as restriction. Additional research would seek to better characterize the effects of health claims on eating disorder risk. Building on international work, it would be useful to evaluate the impact of legislation implemented in other countries and consider its potential to be translated to other contexts. In addition, efforts should be made to generate and examine the potential usefulness of policy solutions that may not be currently under consideration. Such research might include qualitative investigations among individuals at risk or suffering from eating disorders regarding their perceptions of the usefulness of different types of measures, as well as experimental studies.

\section{4 | CONCLUSIONS}

The eating disorder field has a crucial part to play in informing policies targeting the food industry and to ensure that such policies do no harm. Given the lack of scientific evidence serving to inform policymaking, the strategic science model was developed in an attempt to more systematically link scholarship to policy (Roberto \& Brownell, 2017) Within this model, strategic research questions are posed with the goal of providing change agents at the policy level with the data to inform their decisions. Importantly, the strategic science model involves identifying and working with change agents to identify the questions that will inform policy, thereby creating a collaborative model. Thus, we invite the field to engage change agents in their research and come together around a strategic research agenda aiming to gather additional data through which the food environment contributes to eating disorders and how policy may exacerbate or mitigate that risk, including the pathways outlined above. Developing and implementing effective policy approaches aiming to limit the food industry's capacity to continue shaping our food environment in this way is a critical goal for universal prevention efforts and greater involvement from the eating disorders community during the development of such policies is warranted. Our field should consider actively using such policy efforts as a means of improving universal prevention and decreasing environmental risk for eating disorders.

\section{ACKNOWLEDGMENTS}

The authors have no financial relationships relevant to this article to disclose.

\section{CONFLICT OF INTEREST}

The authors have no conflicts of interest to disclose.

\section{ORCID}

Rachel Rodgers PhD (D) http://orcid.org/0000-0002-2582-4220

Kendrin Sonneville ScD, RD (D) http://orcid.org/0000-0002-0359-3919 


\section{EATING DISORDERS}

\section{REFERENCES}

Austin, S. B. (2016). Accelerating progress in eating disorders prevention: A call for policy translation research and training. Eating Disorders, 24 (1), 6-19. https://doi.org/:10.1080/10640266.2015.1034056

Brownell, K. D., \& Frieden, T. R. (2009). Ounces of prevention-The public policy case for taxes on sugared beverages. New England Journal of Medicine, 360(18), 1805-1808. https://doi.org/:10.1056/ NEJMp0902392

Burton, S., \& Kees, J. (2012). Flies in the ointment? Addressing potential impediments to population-based health benefits of restaurant menu labeling initiatives. Journal of Public Policy \& Marketing, 31(2), 232239.

Crino, M., Sacks, G., \& Wu, J. H. (2016). A review of population-level actions targeting reductions in food portion sizes to address obesity and related non-communicable diseases. Current Nutrition Reports, 5 (4), 323-332.

Ebneter, D. S., Latner, J. D., \& Nigg, C. R. (2013). Is less always more? The effects of low-fat labeling and caloric information on food intake, calorie estimates, taste preference, and health attributions. Appetite, 68, 92-97. https://doi.org/:10.1016/j.appet.2013.04.023

English, L., Lasschuijt, M., \& Keller, K. L. (2015). Mechanisms of the portion size effect. What is known and where do we go from here? Appetite, 88, 39-49. https://doi.org/:10.1016/j.appet.2014.11.004

Gearhardt, A. N., Grilo, C. M., DiLeone, R. J., Brownell, K. D., \& Potenza, M. N. (2011). Can food be addictive? Public health and policy implications. Addiction, 106(7), 1208-1212. https://doi.org/:10.1111/j. 1360-0443.2010.03301.x

Hagan, M. M., Chandler, P. C., Wauford, P. K., Rybak, R. J., \& Oswald, K. D. (2003). The role of palatable food and hunger as trigger factors in an animal model of stress induced binge eating. International Journal of Eating Disorders, 34(2), 183-197. https://doi.org/:10.1002/eat. 10168

Haines, J., \& Neumark-Sztainer, D. (2006). Prevention of obesity and eating disorders: A consideration of shared risk factors. Health Education Research, 21(6), 770-782. https://doi.org/:10.1093/her/cyl094

Harris, J. L., \& Graff, S. K. (2011). Protecting children from harmful food marketing: Options for local government to make a difference. Preventing Chronic Disease, 8(5).

Herman, C. P., Polivy, J., Pliner, P., \& Vartanian, L. R. (2015). Mechanisms underlying the portion-size effect. Physiology \& Behavior, 144, 129136. https://doi.org/:10.1016/j.physbeh.2015.03.025

Kerameas, K., Vartanian, L. R., Herman, C. P., \& Polivy, J. (2015). The effect of portion size and unit size on food intake: Unit bias or segmentation effect? Health Psychology, 34(6), 670. https://doi.org/:10. 1037/hea0000160

Lillico, H. G., Hanning, R., Findlay, S., \& Hammond, D. (2015). The effects of calorie labels on those at high-risk of eating pathologies: A prepost intervention study in a University cafeteria. Public Health, 129 (6), 732-739. https://doi.org/:10.1016/j.puhe.2015.03.005

Long, M. W., Tobias, D. K., Cradock, A. L., Batchelder, H., \& Gortmaker, S. L. (2015). Systematic review and meta-analysis of the impact of restaurant menu calorie labeling. American Journal of Public Health, 105(5), e11-e24. https://doi.org/:10.2105/AJPH.2015.302570

Ng, J., Stice, E., Yokum, S., \& Bohon, C. (2011). An fMRI study of obesity, food reward, and perceived caloric density. Does a low-fat label make food less appealing? Appetite, 57(1), 65-72. https://doi.org/:10. 1016/j.appet.2011.03.017

Roberto, C. A., \& Brownell, K. D. (2017). Strategic science for eating disorders research and policy impact. International Journal of Eating Disorders, 50(3), 312-314. https://doi.org/:10.1002/eat.22678

Robinson, T. N., Borzekowski, D. L., Matheson, D. M., \& Kraemer, H. C. (2007). Effects of fast food branding on young children's taste preferences. Archives of Pediatrics \& Adolescent Medicine, 161(8), 792-797. https://doi.org/:10.1001/archpedi.161.8.792

Rodgers, R. F., Ziff, S., Lowy, A. S., Yu, K., \& Austin, S. B. (2017). Results of a strategic science study to inform policies targeting extreme thinness standards in the fashion industry. International Journal of Eating Disorders, 50(3), 284-292. https://doi.org/:10.1002/eat.22682

Schulte, E. M., Avena, N. M., \& Gearhardt, A. N. (2015). Which foods may be addictive? The roles of processing, fat content, and glycemic load. PLoS One, 10(2), e0117959.

Sinclair, S. E., Cooper, M., \& Mansfield, E. D. (2014). The influence of menu labeling on calories selected or consumed: A systematic review and meta-analysis. Journal of the Academy of Nutrition \& Dietetics, 114(9), 1375-1388. https://doi.org/:10.1016/j.jand.2014.05.014

Stice, E., Figlewicz, D. P., Gosnell, B. A., Levine, A. S., \& Pratt, W. E. (2013). The contribution of brain reward circuits to the obesity epidemic. Neuroscience \& Biobehavioral Reviews, 37(9), 2047-2058. https://doi.org/:10.1016/j.neubiorev.2012.12.001

Stirling, L. J., \& Yeomans, M. R. (2004). Effect of exposure to a forbidden food on eating in restrained and unrestrained women. International Journal of Eating Disorders, 35(1), 59-68. https://doi.org/:10.1002/ eat.10232

Swartz, J. J., Braxton, D., \& Viera, A. J. (2011). Calorie menu labeling on quick-service restaurant menus: An updated systematic review of the literature. International Journal of Behavioral Nutrition \& Physical Activity, 8(1), 135. https://doi.org/:10.1186/1479-5868-8-135

Vermeer, W. M., Steenhuis, I. H. M., \& Poelman, M. P. (2014). Small, medium, large or supersize? The development and evaluation of interventions targeted at portion size. International Journal of Obesity, 38(S1), S13-S18. https://doi.org/:10.1038/ijo.2014.84

Yang, Q. (2010). Gain weight by "going diet?" Artificial sweeteners and the neurobiology of sugar cravings: Neuroscience 2010. Yale Journal of Biology \& Medicine, 83, 101-108.

How to cite this article: Rodgers RF, Sonneville K. Research for leveraging food policy in universal eating disorder prevention. Int J Eat Disord. 2018;51:503-506. https://doi.org/10.1002/ eat.22877 